structures subjected to impact loadings. However, the mechanical properties of composite materials under dynamic loading conditions are not well understood, because there are no standard impact test techniques except for the lzod or Charpy impact test methods, where the complex loading system prevents any fundamental interpretation of the data obtained. The purpose of the present study is to determine the interlaminar shear strength of a unidirectional carbon/epoxy laminated composite under impact loading using the conventional split Hopkinson pressure bar. A double-notch specimen (ASTM D3846) is used in the static and impact shear tests. The static interlaminar shear strengths are measured using short beam specimens (ASTM D2344) as well as the double-notch shear specimens. The effect of displacement rate on the interlaminar shear strength is investigated. It is shown that the interlaminar shear strength decreases slightly with increasing displacement rate up to nearly $2.0 \mathrm{~m} / \mathrm{s}$. Microscopic examinations reveal that there is almost no significant difference in the fracture modes between the static and impact shear specimens.

\section{IMP-12: Effect of Strain Rate on the Interlam- inar Fracture Toughness of Zanchor Reinforced Composites}

T. KUSAKA, Ritsumeikan University; M. HOJO, Kyoto University; T. FUKUOKA, Mitsubishi Heavy Industries, Ltd.; M. ISHIBASHI, Shikibo, Ltd.,

E-mail: kusaka@se.ritsumei.ac.jp

The mode I interlaminar fracture behavior of Zanchor, which is a novel out-of-plane reinforcement technique developed by Mitsubishi Heavy Industries and Shikibo, reinforced composite laminates was studied to clear the mechanism of Zanchor reinforcement. The effects of Zanchor density and loading rate on fracture behavior were focused on to acquire the detailed understandings of the mechanism. The experimental results showed that the Zanchor process was remarkably effective for the improvement of mode I interlaminar fracture toughness of composite materials, where the large-scale fiber bridgings were induced by the Zanchor process, which led to the improvement of mode I interlaminar fracture toughness. On the other hand, the mode 1 interlaminar fracture toughness of the Zanchor reinforced composites decreased to some extent with increasing loading rate, where the reduction of mode I interlaminar fracture toughness was a consequence of the loading rate dependence in the generation process of fiber bridgings.

\section{IMP-13: Energy Absorption Characteristics of Carbon Fiber Reinforced Textile Composite Tubes}

Y. YANG, A. NAKAI, H. HAMADA, Kyoto Institute of Technology,

E-mail: nakai@kit.ac.jp

In the case of car collision, the impact energy should be absorbed by an energy absorption member. Traditionally, metallic materials such as steel and aluminum have been used. Recently, there is a considerable amount of published data on the energy absorption characteristics of polymer composite materials, and it is well established that the polymer composite materials achieve higher energy absorption capability than the conventional metals. For the applications in vehicles, square tubes have geometrical advantage as compared with the circular tubes because the flat region in the square tube can be easily assembled with other component parts in automotive constructions. However, because the brittle crack propagation at the corner region in a initial stage is generated, the energy absorption capability of the square tubes is the lower than the circular tubes. Therefore, it is found that the proper design of corner region and material design such as the restraint of the brittle crack propagation at the corner region are needed. In this study, the energy absorption characteristics of pultruded unidirectional carbon composite square tubes were investigated. Furthermore, the energy absorption characteristics of the composite tube consisted of textile fabric were also examined. Here, multi-axial warp knitted fabric and braided fabric were focused. The braiding has the characteristic that fibers are oriented continuously in any kind of shape. Multi-axial warp knitted fabric is that unidirectional fiber bundles are aligned in multi direction and linked with knitted yarn.

\section{IMP-14: Study on Impact Property of Honey- comb Core and Roll Core Sandwich Panels by Drop Weight Test}

O. ITOH, T. OHTSUKA, H. TAMURA, Y. KOBAYASHI, Musashi Institute of Technology,

E-mail: g0461007@sc.musashi-tech.ac.jp

The purpose of this study is to discuss the effects of impact load on honeycomb core sandwich panel (HSP) androll core sandwich panels (RSP). In this study, the drop weight impact test was carried out for HSP and RSP tocompare with each other, because the impact property of RSP that is important for a design is not obvious. The relationships between the absorption energy and maximum deceleration, cell size, and core height were obtainedthrough the test. Following results are obtained. (1) About the rigidity for outside impact, RSP is superior to HSP in small cell size. (2) The maximum decelerations for both of sandwichpanels are influenced by much more cell size than core height. Especially, the influence of cell size of RSP on the maximum deceleration is strong. (3) The rate of energy absorption increase as panel's core height becomes large, regardless of the kind of sandwich panel. As a result, it wasfound that RSP is appropriate to an impact absorber against a heavy and/or high-speed flight body.

\title{
Dinner Cruise
}

